\title{
Research on Basic Theory of Aircraft Carrier Formation
}

\author{
Changpeng $\operatorname{Pan}^{1 \mathrm{a}}$ and Liang $\mathrm{Ma}^{2 \mathrm{~b}}$ \\ ${ }^{1}$ Naval Aeronautical and Astronautical University, Yantai, 264001,China; \\ 2.Department of Surface Ship Command, Dalian Naval Academy, Dalian, 116018,China \\ a285892287@qq.com, b maliang2014@tom.com
}

Keywords: Aircraft carrier formation; Operation; Operation; Command system; Operation coordination

\begin{abstract}
This paper discusses three basic theoretical problems of carrier formation, combat command and operation. It is believed that we should focus on the anti-submarine, air defense and early warning capabilities of the formation of our team, and gradually determine the configuration of each ship in the formation of the aircraft carrier, and the formation of the group as attack formation or defensive formation. The establishment of the aircraft carrier formation command system should take into account the joint operation command and naval contract combat command of the theater. The formation of marshalling command organization is mainly composed of task marshalling and functional grouping and programming. It should focus on maritime control, and give aircraft-carrier formation to sea combat, support cover and other adaptive tasks; To focus on the battle of the battle, to plan and use the carrier formation; Based on the campaign, it can distinguish the internal and external relations, and organize the operational coordination of the aircraft carrier formation. Based on the long - sea transportation security, carry out the staging of the relay.
\end{abstract}

\section{Introduction}

The aircraft carrier formation is a new type of combat force in China's maritime military struggle, which can carry out various combat missions such as the assault on the naval forces, the blockade of the sea and the protection of maritime traffic lines. It is a matter of great concern to the command organs of the military commission, the war zone and the navy. At present, our military lacks the system of carrier formation combat theory, urgently needs to deepen the research, so as to pull the aircraft carrier formation combat operation. It is of great practical significance to further study the operational application of aircraft carrier formation and to enhance the overall construction of the aircraft carrier formation and enhance the capability of maritime military struggle. Based on the practice of operational use of foreign military aircraft carrier formation, this paper explores some common law problems in the operation of aircraft carrier formation, and provides a theoretical reference for our army to use aircraft carrier formation.

\section{Aircraft Carrier Formation Combat Formation}

Aircraft carrier aircraft carrier as the core, with several destroyers, frigates, submarines, combat support ships or comprehensive replenishment ship form, the largest number of number 10, at least not less than $6 \sim 7$. What factors should be taken into consideration in the operational formation of the aircraft carrier group?

The Capability of Anti-Submarine, Air Defense and Early Warning in the Formation of the Team, and the Configuration of Each Ship in the Formation of the Aircraft Carrier is Gradually Determined.

As pattern changed from mechanization to information war, war aircraft carrier all ship configuration matrix had the very big change, but not all ship configuration should consider the basic rules of change, induces has the following three points: first, should first focus on the formation antisubmarine ability consider formation each vessel configuration. The submarine has always been the killer of large ships such as aircraft carriers and combat support ships. It is not easy to be detected, and it is easy to infiltrate the area of formation activities. Even if detected, the 
probability of a submarine attack is far greater than the probability of being sunk by the formation, so the size of the anti-submarine capability is the primary consideration for determining the distance of each ship's configuration. Such as American, French right in front of the aircraft carrier of 100 120 nautical miles, are configured with a certain number of nuclear-powered submarines anti-submarine alert, early use of sonar array to detect enemy submarines, provide formation with the relative safety of motor area; Aircraft carriers around $30 \sim 40 \mathrm{~nm}$ annular region, the need to form a strict system of medium range anti-submarine, stop the breakthrough of outer anti-submarine system submarines, as soon as possible to intercept most submarine launch torpedo attacks, so in the middle must be equipped with a certain number of anti-submarine model ships, carrying the ship-borne anti-submarine helicopter is regional anti-submarine warfare. Second, consideration should be given to the formation of a team's air defense capability to consider the allocation distance of each ship. Formation usually forms a long-range, medium-range and short-range air defense interception system, which is usually blocked by the carrier aircraft and the long-range air defense missile. The special consideration is short range air defense, which is the last one, and if the enemy breaks through the near air defense, the carrier is in danger. Therefore, short-range air defense distance is the main reference data for air defense destroyer configuration distance. Thirdly, it is important to consider the allocation distance of each ship by the formation of the early-warning detection capability. The formation warning detection mainly relies on the carrier-borne aircraft, partly relying on the ship-borne warning radar. In general, if there is a limited warning capability of the aircraft, it will be necessary to add a radar picket ship, or appropriately pull apart the ship's distance and expand the depth of detection. When necessary, it is necessary to set up an independent brigade to provide an early warning for aircraft carrier formation in the 300-400 nautical mile area.

Focus on the Number and Operational Capability of the Carrier-Based Aircraft, and the Group is An Attack Formation or Defensive Formation.

The formation of an aircraft carrier group must first weigh the number of its carrier aircraft and its operational capability. If an aircraft carrier, carrier-borne machine number, in the early warning and effective time enough to sustain the aircraft sorties in air interception, the retained more than two-thirds of carrier-borne machine implementation of assault or other side of the sea, can form a attacking aircraft carrier. If the number of aircraft carriers and carrier-borne aircraft is limited, and the formation of the formation itself is difficult, and the task of covering the amphibious formation or the blockade formation, the formation shall be a defensive formation. During the Pacific war, the us military believes, formation of carrier number should be appropriate, only one aircraft carrier, attack strength is insufficient, more than four aircraft carriers, target quantity is too large and fight harder together, had better maintain in $2 \sim 3$, achieve perfect balance. At the same time that the Japanese in the naval battle of midway to 4 carrier bound to go forward, apparently "put all your eggs in one basket", if can be grouped into two attacking double aircraft carrier, the situation may not be. To this day, the United States navy still maintains a dual carrier formation or a three-carrier formation model. They believe that single-carrier formations are mainly defensive operations, mainly in low-threat maritime areas to implement maritime deterrence; Two aircraft carriers or three carrier formations are suitable for medium and high-intensity maritime operations. Four or more aircraft carriers are not easily formed, unless they are in a low-threat zone to attack a weak enemy. O the falklands war, the British navy task force to "competitive god", "invincible", two light carrier as the core, carry the "harrier" type of aircraft actual less than 20, and a lack of fixed-wing planes airborne early warning, the British timely adopted a defensive marshalling mode, will be "competitive" god, "invincible" broken down into two single aircraft carrier, each equipped with a sufficient number of cover vessels, respectively, with two belong to the falklands southeast and northeast sea, has formed the situation in which early warning to inform each other, each other screen, combined shot down the Argentine long-distance strikes "skyhawk" type of attack more than 40, has reached the local sea area "counter" seize the purpose of the seas. After the war, British and American military experts spoke highly of the flexible formation of British forces. 


\section{Aircraft Carrier Formation Combat Command}

The establishment of an efficient and smooth operational command system for aircraft carrier formation is the basis for joint commanders to carry out operational use of aircraft carrier formation. In combination with the operational practice of aircraft carrier formation, this paper focuses on the analysis of the operational command system and the internal marshalling of the aircraft carrier.

The Establishment of a Command System Should Take into Account the Joint Operation Command of the Theatre and the Command Of Naval Contracts.

Throughout the Pacific war and modern local war, the aircraft carrier formation as maritime mobile assault force, the battle command system experienced a process of constant development and change, the overall trend is that under the command of independent war to the war zone joint operations with the navy combat command system of combining contract change. In the Pacific war, the aircraft carrier as the backbone of the navy assault force, generally included in the naval battle command system, whether the U.S. navy, the British navy, or the Japanese navy, adopt the navy (battlestation, military department, general staff) -- - aircraft carrier fleet level 3 command system. The advantage of this command system is that it is convenient for the navy to strengthen the operational guidance of the aircraft carrier formation, and form a specialized combat command chain and combat support system. The disadvantage is that it is not conducive to the joint operation, which often happens when the aircraft carrier group is blindly seeking the main decisive battle, ignoring the cover of the combat troops, especially the amphibious units.

In modern local war, the aircraft carrier battle command system change, the main countries involved are to recognize aircraft carrier as "fist" strength of joint operations globally, must be a unified command, at the same time, considering the aircraft carrier battle command of professional features, gradually formed mainly war zone joint operations to two or morethings contract naval combat command of hybrid system, the joint operations command (contract) (permanent theater headquarters, built based on a navy contract operations command) -- - aircraft carrier fleet level 3 command system. As Britain during the falklands war, formed as the British royal navy command as the main body, to absorb air command, army headquarters related members to form a joint operations command in wartime commander (for field house admiral) - task force commander (Woodward rear admiral) - aircraft carrier (Woodward rear admiral part-time) level 3 command system; During the gulf war, the americans formed a central zone (commander admiral, popular science, watts), fifth, seventh fleet joint forces (central headquarters navy commander Arthur vice admiral) - aircraft carrier formation (Persian gulf, red sea fleet) level 3 command system.

The Marshalling of the Command Organization Shall be Composed of Task Marshalling and Functional Grouping and Programming.

Aircraft carrier fleet command marshalling, essence is to solve the problem of what form to differentiate the command functions of internal division of labor and the core is how to effective command and control aircraft carrier and carrier air wing cover, combat ships, the service safeguard ships. Throughout a major military power command marshalling, generally there are three kinds of modes: one is grouped in function, grouped into battle command center, communications, intelligence and so on a number of functional departments, the battle of marshalling modes suitable for hierarchical command structure; Second, according to the combat mission organization, organization of air operations, anti-submarine warfare, air defense operations, information operations, service guarantee, such as certain tasks departments, this kind of organization mode is the United States, Britain, France and other countries to take the idiomatic patterns, suitable for contract tactical level of command. Third, according to the formation of the combat process, more suitable for the information level, the fast pace of the tactical level command structure. According to today's major powers idiomatic task model, in general, air operations by formation directly under the command of the air combat command branch command, usually by the aircraft captain concurrently formation as deputy commander and air combat commanders; The director of the anti-submarine warfare center, the director of the air defense operations center and the director of the information operations center shall be the officers who are familiar with the relevant functions. The head of the service department shall be the officer of the security base. 


\section{Carrier Formation Combat Implementation}

Aircraft carrier as maritime mobile assault force, is the joint operations took control sea, cover amphibious attack in the key strength, reasonable given aircraft carrier operations, meticulous planning, aircraft carrier operations, flexible organization carrier fleet operational synergy, effective to provide security, far from the sea aircraft carrier is the joint operations commander to organize the implementation of the four key link of aircraft carrier operations.

\section{The Adaptive Tasks, Such as the Naval Operation and Support Cover, are given to the Aircraft Carrier in the Control of the Sea.}

Aircraft carrier can perform the following six kind of combat missions: one is the battle of deterrence missions during the war crisis, through the seas, the naval exercises, according to maritime military presence, squeeze the enemy maritime space, limiting the enemy sea motor, create a favorable maritime situation; The second is the assault on the enemy's maritime forces group, and by means of information warfare, maritime maneuvers and rapid attacks, to wipe out the enemy's maritime mobile formation and seize control of the operational sea area; The third is to participate in attacks against enemy port bases, industrial facilities and other strategic and operational targets, reduce the potential of the enemy's war, and force the enemy to stop military operations. Fourth, to participate in the island offensive operations, establish maritime control areas, cover the sea transport; Fifth, participating in the protection of maritime traffic lines, seizing control of local maritime areas, and carrying out regional cover for the transport fleet formation; The sixth is to participate in the naval blockade operation, cover the blockade force group to establish the sea blockade system, the assault enemy anti-blockade forces.

As a joint operational commander, he must firmly establish the ideology of "taking control of the sea", and flexibly assign his combat mission according to the purpose of the campaign. In general, the aircraft carrier group should be given priority in the task of maneuvering the enemy's naval forces to seize control of the sea. Secondly, the aircraft carrier is given the task of carrying out the sea cover, such as covering the Marine interceptor in the area outside the blockade zone, covering the landing and sending formations to carry out the sea transport; When the aircraft carrier group has a strong capability of attacking the shore, it can appropriately give its assault port and airport task; Under normal circumstances, should avoid to give aircraft direct support sas assault on land, because the aircraft compared to shore-based aircraft, small amount of payload and operational capability is weak, on the other combat radius is less than the shore-based aircraft, vulnerable to the counter of the shore-based aviation, lost the aircraft carrier flexible advantage.

\section{Focus on the Campaign Connection, Distinguish the Internal and External Relations, and Organize the Operational Coordination of Aircraft Carrier Formation.}

Synergy has always been a key issue in operations, especially in joint operations. As an important part of joint naval operations, the aircraft carrier group is only one member of the joint operation in spite of its important status and arduous task. Coalition commanders should focus on the battle, trying to control good aircraft carrier internal and external relations, elaborate organization carrier fleet operational synergy, ensure that the aircraft carrier formation can play a proper performance.

Coalition commanders to contact, contact forces and battle space operations, to distinguish the internal relations and aircraft carrier aircraft carrier and other war forces of external relations, organize internal and external coordination aircraft carrier formation. In general, the internal coordination of the aircraft carrier formation is carried out by the specific organization of the formation commander, which mainly includes the detection and early warning, anti-submarine and surprise coordination of the carrier aircraft. The aircraft carrier and the destroyer escort, along with the supply ship coordination. The external coordination of the aircraft carrier formation is carried out by the joint operational commander and the fleet commander according to the power allocation. The coordination of aircraft carrier formation and air combat cluster, missile combat cluster, 
information warfare cluster and other forces is organized by joint operational commanders; The aircraft carrier group is organized by the commander of the fleet in coordination with the joint maneuver formation, the amphibious assault formation, the submarine force group, the mobile security group and other forces. During the gulf war, the U.S. combat aircraft carrier group consisted mainly of red sea formations and Persian gulf formations. In order to effectively organize the cooperation between the aircraft carrier formation and related combat forces, the us military has adopted a more flexible cooperative approach. In the stage of "desert shield" sea blockade, aircraft carrier to undertake major combat operations, the main collaborative deterrence and other three task force to implement sea blockade, collaborative soldiers, the Marine corps, air force; In "desert storm" stage, the central theater commander will transfer aircraft carrier to the air force command and air joint forces command to implement a unified command, two aircraft carrier separately from the red sea, Persian gulf coordinated air force implement back two directions, key to assault on littoral targets. In stage "desert saber", the red sea fleet continue to accept the air joint forces command control, key target in the southwest of bear on Iraq assault, with the air force airborne army 18 ground assault "left hook". The Persian gulf formations were built by the naval command, supporting the landings and the Marine expeditionary force of 17,000 on the Kuwaiti coast, and the main diversion of the Iraqi forces in Kuwait. It is worth learning from the experience of the flexible organization of American military aircraft carrier.

\section{References}

[1] Xu Yanguo, Hu Xuecheng. Integrated radio frequency technology and its development. Journal of Chinese Academy of Electronic Science and technology, 2009, 12 (6):552-559

[2] Lin Zhiyuan. Development and key technology of multifunction integrated RF system. Telecommunication technology, 2006, 5:1-5

[3] Meng Xiangling. Advanced multifunction RF concept. Radar and detection technology, 2009 (4): 20-22

[4] GREGORY C TAVIK. The advanced multifunction RF concept. IEEE Transactions on microwave theory and techniques, 2005,53(3): 1009-1020

[5] Yu D, Peng L. When does Inferring Reputation Probability Countervail Temptation in Cooperative Behaviors for the Prisoners' Dilemma Game? [J]. Chaos, Solitons \& Fractals, 2015, 78: 238-244.

[6] M. Pla, P. Hernández, B. Ari?o, J.A. Ramírez and Isabel Díaz: Food Chemistry, Vol. 100 (2007) No.1, p.165.

[7] R.R. Pullanagari, I.J. Yule and M. Agnew: Meat Science, Vol. 100 (2015), p.156.

[8] Saudland, A., Wagner, J., Nielsen, J. P., Munck, L., N?rgaard, L. and Engelsen, S. B: Applied Spectroscopy, Vol. 54 (2000) No.3, p.413.

[9] Balabin, R. M. and Smirnov, S. V: Analytica Chimica Acta, Vol. 692 (2011) No.1-2, p.63.

[10] Leardi, R. and N?rgaard, L: Journal of Chemometrics, Vol. 18 (2004) No.11, p.486. 